\title{
Fkh5-deficient mice show dysgenesis in the caudal midbrain and
}

\section{hypothalamic mammillary body}

\author{
Roland Wehr, Ahmed Mansouri, Tine de Maeyer and Peter Gruss \\ Max Planck Institute for Biophysical Chemistry, Department of Molecular Cell Biology, Am Fassberg, 37077 Goettingen, Germany
}

\section{SUMMARY}

The murine winged helix gene Fkh5 is specifically expressed in the developing central nervous system (CNS). Early embryonic Fkh5 expression is restricted to the mammillary body region of the caudal hypothalamus, midbrain, hindbrain and spinal cord. Postnatally, signals persist in specific nuclei of the mammillary body and in the midbrain. We generated Fkh5 deficient mice by homologous recombination to assess its in vivo function. At birth, Fkh5-deficient mice are viable and indistinguishable from wild-type and $\boldsymbol{F k h 5}$ heterozygous littermates. However, about one third die within the first two days and another fifth before weaning. Surviving Fkh5-deficient mice become growth retarded within the first week and remain smaller throughout their whole life span. $F \boldsymbol{k h} 5$-deficient females on $129 \mathrm{~Sv} \times \mathrm{C57BL} / 6$ genetic background are fertile, but do not nurture their pups. More detailed analysis of Fkh5deficient brains reveals distinct alterations in the CNS. In the midbrain, mutant mice exhibit reduced inferior colliculi and an overgrown anterior cerebellum. Furthermore, the hypothalamic mammillary body of Fkh5deficient brains lacks the medial mammillary nucleus. These results suggest that $F \boldsymbol{k h} 5$ plays a major role during CNS development.

Key words: Fkh5, fork head, winged helix, midbrain, inferior colliculi, hypothalamus, mammillary body, mouse

\section{INTRODUCTION}

One attempt to understand the complex functional and regional organisation of the mature CNS is the analysis of genetic mechanisms underlying its development. The identification of developmental control genes in Drosophila melanogaster has immensely expanded our knowledge about these processes. The conservation of such regulatory genes allows us to isolate the mammalian homologs and to dissect the genetic network crucial for CNS development and function. Particularly, the expression and functional analysis of murine homologs, like Dlx (Price et al., 1991; Qiu et al., 1995), En (Joyner et al., 1985; Wurst et al., 1994), Emx (Simeone et al., 1992a; Pellegrini et al., 1996), Otx (Simeone et al., 1992b; Matsuo et al., 1995; Acampora, 1995), Pax (reviewed by Chalepakis et al., 1993) and Wnt (McMahon and Bradley, 1990; Thomas and Capecchi, 1990) reveal their importance in the CNS.

Recently, a new family of transcription factors containing the fork head domain has been identified. The prototype gene fork head ( $f k h)$, a region-specific homeotic gene in Drosophila promotes terminal as opposed to segmental development (Weigel et al., 1989). Conservation of the DNA binding sequence, also termed the winged helix domain on the basis of X-ray crystallographic analysis (Clark et al., 1993), has led to the isolation of new family members from organisms ranging from yeast to man (reviewed by Kaufmann and Knöchel, 1996). Murine winged helix genes, such as $H N F 3 \beta$ and $B F 1$, have been shown to play a role in the developing CNS. $H N F 3 \beta$ is mainly expressed in the node, notochord, floor plate and gut
(Ang et al., 1993; Monaghan et al., 1993; Sasaki and Hogan, 1993). The $H N F 3 \beta$ null mutation results in midline structure defects, affecting notochord and spinal cord development (Ang and Rossant, 1994; Weinstein et al., 1994). Ectopic HNF-3 $\beta$ expression in mid- and hindbrain changes the expression of floor plate-specific genes yielding abnormal neural patterning (Sasaki and Hogan, 1994). BFl is expressed in the developing telencephalic neuroepithelium and in the eye (Tao and Lai, 1992). Loss of function of $B F I$ leads to a substantial reduction in the size of the cerebral hemispheres (Xuan et al., 1995). These observations underline a crucial role of fork head/winged helix genes for CNS development.

$F k h 5$, also termed HFH-e5.1 (Ang et al., 1993) or $M f 3$ (Sasaki and Hogan, 1993; Labosky et al., 1996) is expressed during embryonic development from day 7.5 p.c. onwards in CNS and presomitic mesoderm (Ang et al., 1993; Kaestner et al., 1996). Our expression analysis of midgestation embryos reveals that $F k h 5$ is restricted to specific regions in the spinal cord, hindbrain, midbrain and mammillary body region of the hypothalamus. After birth, expression is maintained in the mesencephalon and mammillary body. This expression pattern suggests $F k h 5$ to be an important regulator of development and maintenance of these structures.

In order to elucidate the in vivo function of $F k h 5$, we generated a mouse strain carrying a null mutation in the $F k h 5$ gene by homologous recombination. Homozygous Fkh5-/mice are born live, however about one third die shortly after birth, the others become growth retarded within the first week. Another fifth die before weaning. Histological analysis of the 
CNS demonstrates that $F k h 5$ plays a critical role during caudal midbrain and hypothalamus development. Further, the structural changes of the hypothalamic mammillary body in Fkh5-/- mice are presumably associated with severe deficits in nurturing behavior.

\section{MATERIALS AND METHODS}

\section{Histology and in situ hybridisation}

Noon of the day after copulation was considered as day 0.5 p.c. Embryos and postnatal brains for in situ hybridisation were fixed overnight in $4 \%$ PFA/PBS at $4^{\circ} \mathrm{C}$, and either dehydrated in methanol or embedded in paraffin using routine procedures. For histology, embryos and tissues were fixed overnight in Bouin's solution at room temperature, sectioned $(10 \mu \mathrm{m})$ and stained with cresyl violet using standard protocols. Whole-mount in situ hybridisation of embryos was performed as described by Wilkinson (1992) using a digoxigeninlabeled antisense RNA probe. For radioactive in situ hybridisation, embryos and tissues were sectioned $(8 \mu \mathrm{m})$ and processed as previously described by Stoykova and Gruss (1994). Whole-mount $\beta$-galactosidase staining was performed as described by Allen et al. (1988).

\section{Construction of the targeting vector}

A $14 \mathrm{~kb}$ genomic clone was isolated from a mouse 129/Sv genomic library (kindly provided by A. Berns, Amsterdam) using a Fkh5 cDNA probe. A $2.4 \mathrm{~kb} \mathrm{BamHI} / \mathrm{SacII}$ genomic fragment containing the 3 '-part of exon 1 and the $5^{\prime}$-part of exon 2 including the ATG and the fork head domain was replaced by the PGK-Neo expression cassette in transcriptional orientation (Soriano et al., 1991). The targeting

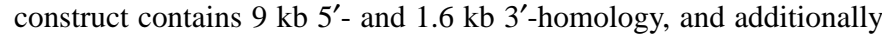
the HSV-TK at the end of the 3'-homology for negative selection (Mansour et al., 1988).

\section{ES-cell transfection, screening and generation of Fkh5-/- mice}

R1 ES-cells were cultured as described by Robertson (1987) and transfected with $25 \mu \mathrm{g}$ linearized targeting vector by electroporation (Bio-Rad Gene Pulser, $250 \mathrm{~V}, 500 \mu \mathrm{F}$, electrode distance $0.4 \mathrm{~cm}$ ). G418 and gancyclovir selection was applied 24 hours after transfection, resistant clones were isolated after 8 days of selection. Genomic DNA from these clones was digested with BamHI and screened by Southern analysis using a $3^{\prime}$ external probe. Positive clones were confirmed with neomycin and internal probes $(B g l I I$ digested genomic DNA). Chimeric mice were generated by morula aggregation according to the method of Robertson (1987) and germ line transmission was assessed by scoring the $\mathrm{F}_{1}$ generation for the agouti coat colour, and Southern analysis. Germline chimeras were mated to mice of $129 / \mathrm{Sv}$ or C57BL/6 genetic background.

\section{Nurturing behavior}

Behavioral experiments were performed with $F k h 5-/-$ mice of the genetic background $129 \mathrm{~Sv} \times \mathrm{C} 57 \mathrm{BL} / 6\left(\mathrm{~F}_{2}\right.$ generation) that were 3-4 months old. Controls always included wild-type mice of the same litter. Fkh5-l- and wild-type intercrosses of the $\mathrm{F}_{2}$ generation were set up in parallel. Pregnant females were kept in separate cages. After birth, mothers were observed for their nurturing and nestbuilding behavior. For fostering experiments, pups were removed from $F k h 5-/-$ mothers and fostered to a wild-type mother. This was also done vice versa. The wild-type mothers had the same genetic background and age.

\section{RESULTS}

\section{Fkh5 expression analysis during CNS development}

Initially, we have studied the expression of Fkh5 during embryonic development from day 10.5 p.c. onwards and postnatally. Earlier studies of Ang et al. (1993) and Kaestner et al.
(1996) showed that $F k h 5$ RNA expression is first detected at day 7.5 p.c. in the posterior primitive streak mesoderm of the developing embryo. At day 8.5 p.c., Fkh5 is present in the open neural plate, spinal cord, presomitic and transiently in somitic mesoderm. After closure of the neural tube at day 9.5 p.c. $F k h 5$ transcripts are abundant along the neural tube except in the rostral forebrain. Expression in the spinal cord is restricted to the ventromedial ventricular zone. At midgestation stage, motor neuron columns of the ventrolateral neural tube are strongly positive.

At day 10.5 p.c., $F k h 5$ transcripts in the developing brain are detected in the mammillary body region, the thalamus, in the rostral and caudal midbrain, and in the hindbrain (Fig. 1A). Interestingly, the expression in the caudal midbrain demarcating the midbrain-hindbrain boundary shows a gradient, which diminishes at day 12.5 p.c. At this stage, $F k h 5$ expression in the anterior midbrain is retracted from the pretectum and forms a rostral to caudal gradient (Fig. 1B). This gradient becomes prominent at day 14.5 p.c. showing its rostral boundary at the posterior commissure. Additional signals are observed in the ventricular zone of the metencephalon and myelencephalon (Fig. 1C,D). More extensive in situ hybridisation analyses of postnatal brains identifies the precise localisation of $F k h 5$ in differentiated nuclei of the mammillary body and in the mesencephalon. Three weeks after birth, Fkh5 is expressed in the medial mammillary (Fig. 1E,F) and faintly in the dorsal premammillary and tuberomammillary nuclei (data not shown). Fkh5 signals in the mesencephalon are present in the intermediate and deep gray layers of the superior colliculi (Fig. $1 \mathrm{G}, \mathrm{H})$. This postnatal expression of Fkh5 in the brain still persists in 3-month old mice (data not shown). No postnatal expression is observed in the inferior colliculi, the metencephalon and myelencephalon, or in the spinal cord.

\section{Generation of Fkh5-/- mice}

To disrupt the $F k h 5$ locus, we used a positive-negative selection strategy in the 129/Sv derived ES-cell line R1 (Fig. 2A-C) (Mansour et al., 1988; Nagy et al., 1993). Six from 211 clones were correctly targeted. Chimeras from two different cell clones were produced by morula aggregation and bred to $129 / \mathrm{Sv}$ mice for histological analysis. Interbreeding of $F k h 5+/-$ mice results in a normal Mendelian ratio of homozygous mutants at birth, indicating that the absence of Fkh5 is not lethal in utero (Table 1). However, about $30 \%$ of Fkh5-/mice die within the first 2 days and another $20 \%$ before weaning (Table 1; Fig. 2D). A few days after birth, homozygous mice become growth retarded and clearly distinguishable from their $F k h 5+/-$ and wild-type littermates (Fig. 2F). Surviving Fkh5-/- animals remain proportionally smaller (25$30 \%$ ) as shown in growth curves (Fig. 2E) and exhibit a normal life span. Since mating performance of $F k h 5$ null-mice on $129 / \mathrm{Sv}$ background was poor, we intercrossed the $F k h 5$ mutation into C57BL/6 genetic background. Again, heterozygous crosses resulted in normal Mendelian ratios of neonatal mice (Table 1). Pregnancies of Fkh5-/- mothers (F2: C57BL/6 $\times 129 / \mathrm{Sv})$ were normal and carried out to term $(n=21)$. However, they neglect their pups and show neither nestbuilding nor nursing activities (Fig. 3A,B). Therefore, all pups died shortly after birth. Even after multiple pregnancies $(n=4)$ the nurturing behavior of $F k h 5-1-$ mothers did not improve. Fostering experiments $(n=9)$ of $F k h 5-/-$ and wild-type pups to 
a wild-type or Fkh5-/- mother could assign the defect to the mutant mothers. Histological analysis of the mammary glands did not reveal any abnormality in development or function (data not shown), rejecting the possibility that the nurturing abnormality is secondarily due to a lactation defect. This is supported by the observation that some pups had milk in their stomachs.

\section{Abnormal midbrain development in Fkh5-/- mice}

On the basis of $F k h 5$ expression we investigated the midbrain of Fkh5-/- mice from early embryogenesis onwards. Starting at day 10.5 p.c., we could not detect any obvious alteration in the midbrain structures using the molecular markers Pax5 and Pax7 (Fig. 4) (Jostes et al., 1991; Asano and Gruss, 1992). Histological analysis of day $10.5-18.5$ p.c. Fkh5-/- embryos has not revealed any defect in the midbrain (data not shown). However, postnatal analysis of 3-week old brains has revealed overt morphological malformations in the posterior midbrain. The two rounded posterior eminences of the quadrigeminal plate, the inferior colliculi, are reduced near the midline and partially covered by the anterior cerebellum, whereas their lateral parts are normal in size and shape compared to the wild-type brain (Fig. 5A,C). Interestingly, the brains of $F k h 5+/-$ mice show an intermediate phenotype (Fig. 5B), arguing for a semi-dominant effect of the Fkh5 mutation. This phenotype persists into adulthood. To antagonize this malformation, we intercrossed Fkh5-/- mice with Pax7/lacZ knock out mice (Mansouri et al., 1996), since Pax7 is a marker for the superior colliculi in the anterior midbrain (Stoykova and Gruss, 1994). We analysed brains of mice which were wild-type, heterozygous or homozygous for the Fkh5 mutation and always heterozygous for the Pax7 transgene. Pax7 expression data clearly showed that the superior colliculi are not affected. However, the distance between anterior cerebellum and the superior colliculi is clearly reduced due to the reduction of the inferior colliculi and the overgrowth of the anterior cerebellum (Fig. 5D,F). Again, Fkh5+/mice exhibit an intermediate phenotype (Fig. 5E). Histological analysis reveals a size reduction of the medial inferior colliculi and an abnormal growth of the most anterior cerebellar lobe, the lobulus culmen (Fig. 5G-I). Whereas in Fkh5+/mice the size of the lobulus culmen is normal, a prominent elongation can be seen in Fkh5-/mice.

\section{Loss of hypothalamic structures in Fkh5- null mice}

The posterior end of the hypothalamus is demarcated by the mammillary body, which is subdivided into a small lateral and a large medial region. Mammillary body neurons are generated from the neuroepithelium of the mammillary recess between day $12.0-18.0$ p.c. in rat, this is equivalent to day $10.0-16.0$ p.c.
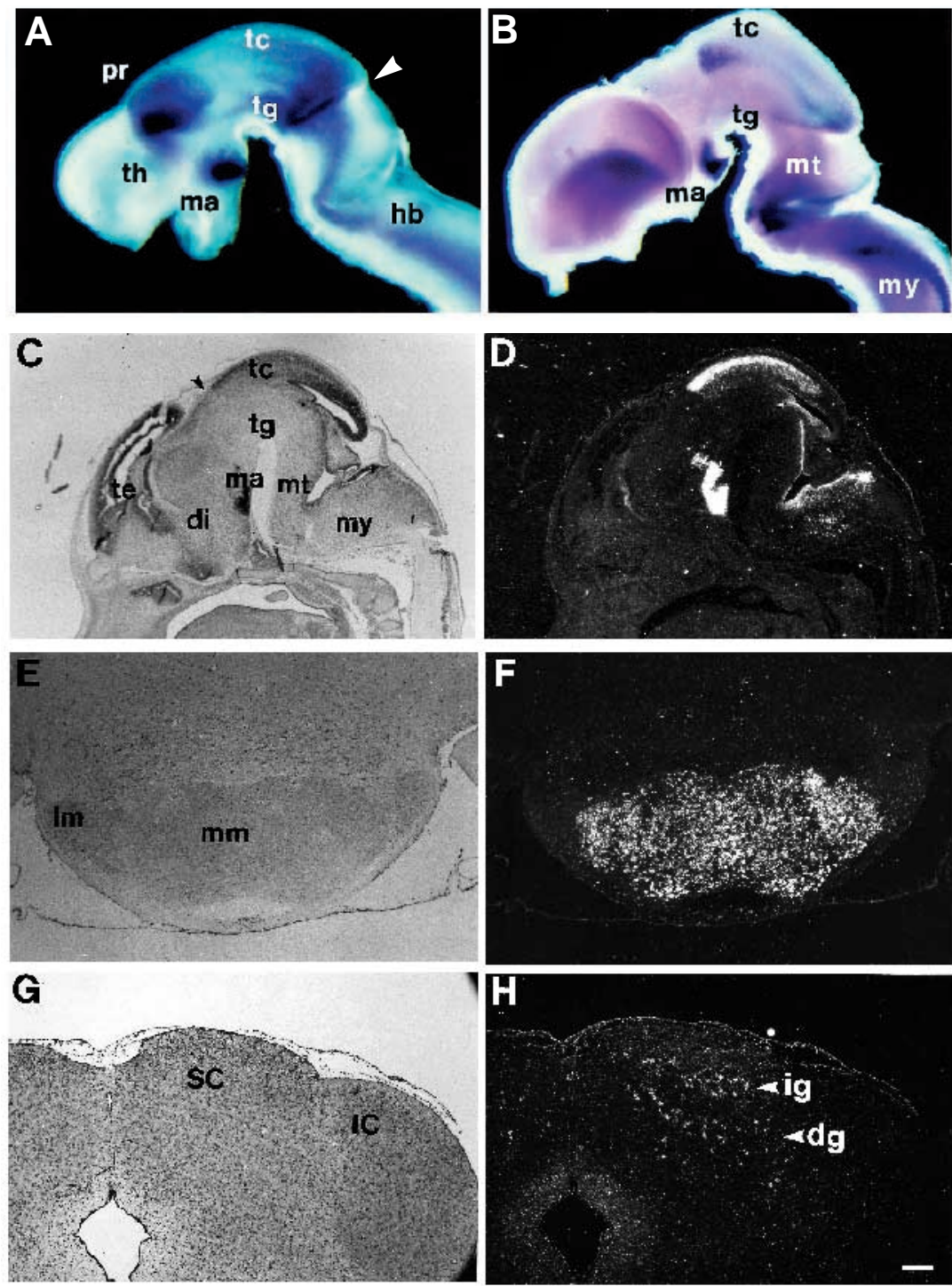

Fig. 1. Fkh5 expression during embryonic development and after birth. Whole-mount in situ hybridisation of (A) day 10.5 p.c. and (B) day 12.5 p.c. isolated brains, lateral views. Radioactive in situ hybridisation (C,D) of a day 14.5 p.c. embryo, parasagittal sections and (E-H) of a 3-week old brain, coronal sections. (A) At day 10.5 p.c., restricted expression in the CNS is observed in hindbrain, at the midbrain-hindbrain boundary (white arrowhead), in the anterior mesencephalic tectum and pretectum, thalamus and mammillary body region. (B) At day 12.5 p.c., expression in midbrain is retracted from the pretectum and diminishes in the caudal midbrain. Expression is detected in the dorsal myelencephalon and restricted to certain nuclei at the boundary between myelencephalon and metencephalon, possibly the olivary nuclei. Staining in telencephalon is due to unspecific background. (C,D) In midgestation brain at day 14.5 p.c., Fkh5 expression is detected in the mammillary body region, the anterior tectum, in the caudal tegmentum, the mesencephalon and the myelencephalon. (E,F) Three weeks after birth, $F k h 5$ expression is confined to the medial mammillary nucleus of the mammillary body. $(\mathrm{G}, \mathrm{H})$ Expression in midbrain is detected in the intermediate and deep grey layers of the superior colliculi.dg, deep grey layer; di, diencephalon; hb, hindbrain; ic; inferior colliculus; ig, intermediate grey layer; $1 \mathrm{~m}$, lateral mammillary nucleus; ma, mammillary body region; $\mathrm{mm}$, medial mammillary nucleus; mt, metencephalon; my, myelencephalon; pr, pretectum; sc, superior colliculus; te, telencephalon; tc, mesencephalic tectum; tg, mesencephalic tegmentum; th, thalamus. Scale bar indicates $500 \mu \mathrm{m}(\mathrm{A}-\mathrm{D}) ; 100 \mu \mathrm{m}(\mathrm{E}-\mathrm{H})$. 
A

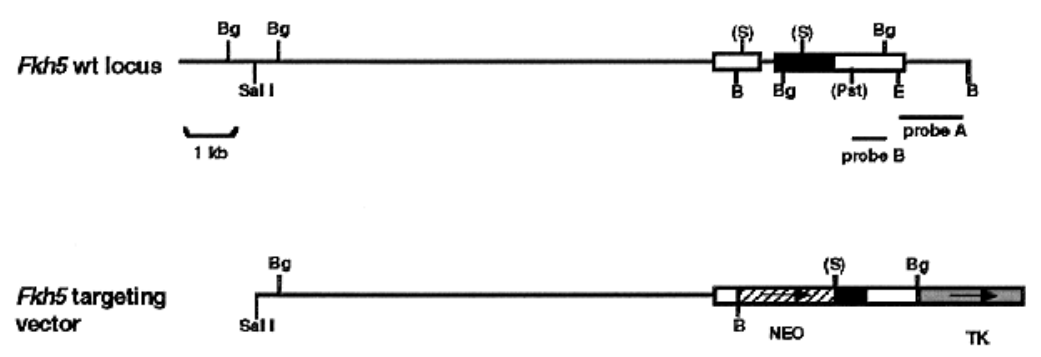

B

$$
\text { -1- wt wt +1- }+-+
$$

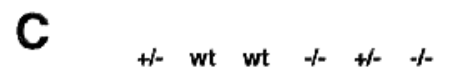

$4.7 \mathrm{~kb}$ $4.3 \mathrm{~kb}$ -

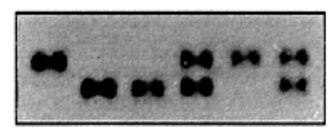

D

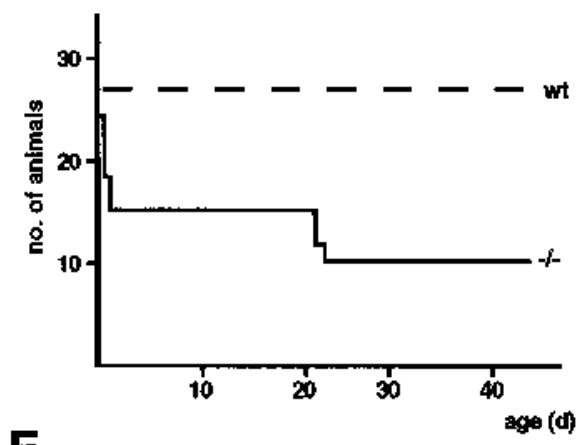

$\mathbf{E}$
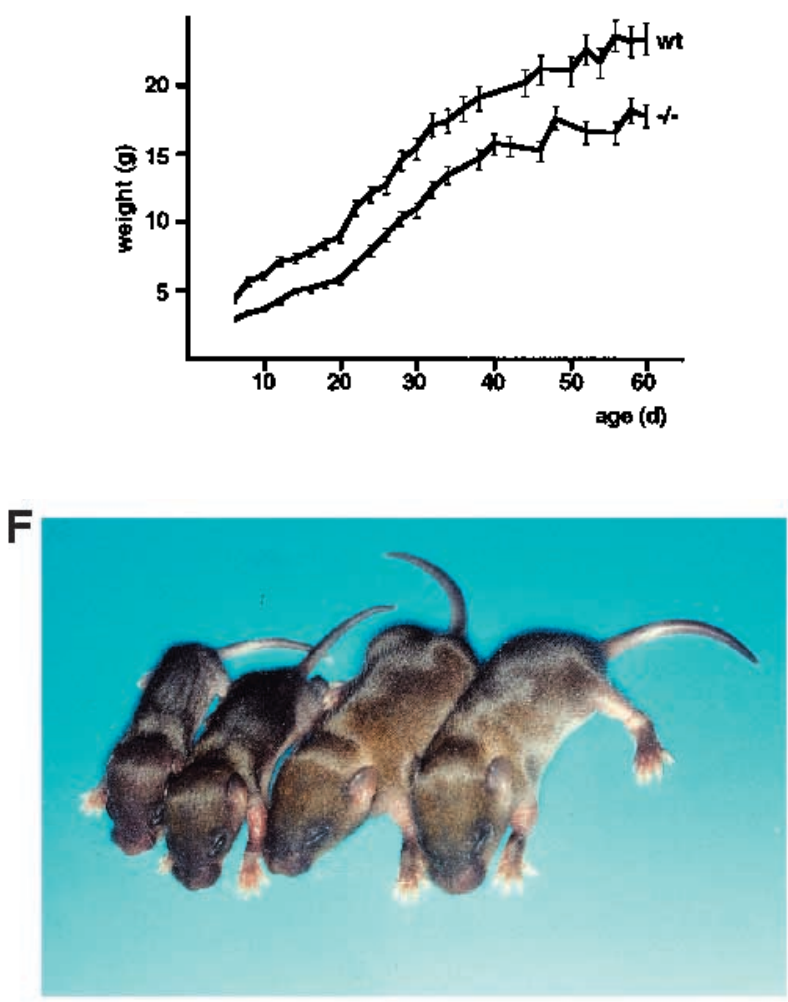

Fig. 2. (A) Fkh5 targeting and genotypic analysis. Top lane: Genomic organisation of the $F k h 5$ gene. Open boxes represent exons, the black box indicates the coding region of $F k h 5$. Probes A (external probe) and B (internal probe) were used for genotyping ES-cell clones and mice. Middle lane: diagram of the Fkh5 targeting vector. The 3' part of the first exon and the 5' part of the second exon, containing the ATG and the fork head domain were deleted and replaced by the PGK-Neo cassette as positive selection marker. HSV-TK was introduced as negative selection marker into the $3^{\prime}$ end of the targeting construct. Black arrows show the transcriptional orientation of both markers. Bottom lane: structure of the Fkh5-/- allele. B, BamHI; Bg, BglII; E, EcoRI; NEO, PGK-Neo selection cassette; Pst, PstI; S, SacII; TK, HSV-TK selection cassette. Restriction sites in brackets were only partially mapped. (B) Southern blot analysis of genomic DNA from mouse tails digested with Bam $\mathrm{HI}$ and probed with the external probe A. The lower band corresponds to the wild-type allele (4.3 kb), the upper band to the mutated allele $(4.7 \mathrm{~kb})$. (C) Southern blot analysis using BglII and the internal probe B. The lower band represents the wild-type allele $(1.8 \mathrm{~kb})$, the upper band the mutant allele $(11.5 \mathrm{~kb})$. (D) Mortality diagram of $F \mathrm{kh} 5-/-$ mice in comparison to wild-type mice on $129 / \mathrm{Sv}$ genetic background. A total of $n=11$ litters of heterozygous crosses were analysed and counted daily. $F k h 5-/-$ mice die in two phases: shortly after birth (30\%) and before weaning (20\%). Fkh5+/- mice show the same mortality rate as wild-type mice (data not shown). (E) Growth curves of male $F k h 5-/-$ and wild-type mice on $129 / \mathrm{Sv}$ genetic background. A total of $n=11$ litters of heterozygous crosses were analysed. Compared to wild-type mice, the growth rate of $F k h 5-/-$ mice is slower until weaning. Afterwards, the growth rate is similar, while $F k h 5-/-$ mice show a $25-30 \%$ weight reduction throughout their life span. Fkh5+/- mice have the same growth rate as wild-type animals (data not shown). Standard deviations are shown. (F) Typical example showing the Fkh5-l- mutant (left) in comparison to wild-type (right) mice 1 week after birth. -/-, homozygous mutant; +/-, heterozygous mutant; wt, wild type.

in mice (Altman and Bayer, 1986). Specific nuclei in that brain region become microscopically distinguishable from day 18.5 p.c. onwards. From early embryonic development on, Fkh5 transcripts are abundant in the mammillary body region and persist into adulthood in differentiated nuclei. This expression profile suggests a role for $F k h 5$ during differentiation or main- tenance of the mammillary body region. Analysis of Fkh5-/mice revealed that the medial mammillary body region shows extensive abnormalities compared to $F k h 5+/-$ and wild-type littermates.

Histological analysis of the terminal differentiated mammillary body of 3 -week old Fkh5-/- mice reveals that the 
Table1. Genotypic analysis of mice and embryos on 129/Sv and 129/Sv $\times$ C57BL/6 genetic background generated by Fkh5 heterozygous intercrosses

\begin{tabular}{|c|c|c|c|c|c|c|}
\hline \multirow[b]{2}{*}{ Age } & \multicolumn{3}{|c|}{$129 / \mathrm{SV}$} & \multicolumn{3}{|c|}{$\begin{array}{l}129 / \mathrm{Sv} \times \\
\mathrm{C} 57 \mathrm{BL} / 6\end{array}$} \\
\hline & wt & $F k h 5+/-$ & Fkh5-I- & wt & $F k h 5+/-$ & Fkh5-I- \\
\hline E $10.5-18.5$ p.c. & nd & nd & nd & $23(21.9 \%)$ & $59(56.1 \%)$ & $27(25.7 \%)$ \\
\hline p0 & $80(25.7 \%)$ & $154(49.5 \%)$ & $77(24.8 \%)$ & $71(25.4 \%)$ & $139(49.6 \%)$ & $70(25.0 \%)$ \\
\hline 4 weeks & $80(25.7 \%)$ & $151(48.6 \%)$ & $33(10.6 \%)$ & $69(24.6 \%)$ & $138(49.3 \%)$ & $29(10.3 \%)$ \\
\hline
\end{tabular}

Embryos and mice were genotyped by Southern blot analysis of yolk sac and tail DNA.

prominent medial mammillary nucleus is absent, disturbing the layered structure of the whole mammillary body (Fig. 6A-D). Thus, the shape of the adjacent supramammillary nucleus is altered which then extends more ventrally. Other nuclei of the ventro-caudal hypothalamus appear less compact and compensate for the absence of the medial mammillary nucleus (Fig. 6C,D). Also the reduced distance between the third ventricle and the mammillary recess (surrounded by the arcuate nucleus) in Fkh5-/- mice can be explained by the absence of the mammillary nucleus and is not due to size differences between mutant and wild-type brains (Fig. 6A,B). Although $F k h 5$ is expressed in the dorsal premammillary and tuberomammillary nuclei, there are no obvious alterations detectable in these mammillary body structures (Figs 6A,B, 7E,F). In contrast to the midbrain phenotype, no alterations in the mammillary body of $F k h 5+/-$ brains are observed.

However, Fkh5 expression within the mammillary body region starts at day 10.5 p.c., a phenotype is not detected until day $16.5-18.5$ p.c.. In day 16.5 p.c. Fkh5-/- mice the mammillary body appears smaller compared to wild-type littermates. This size reduction is mainly confined to the medial region which will give rise to the medial mammillary nucleus (Fig. 7A,B). Different nuclei of the mammillary body first become clearly distinguishable at day 18.5 p.c. Whereas the lateral, premammillary and supramammillary nuclei appear normal there is no proper compact nuclear structure giving rise to the prominent medial mammillary nucleus (Fig. 7C,D). Therefore, the mutant mammillary body appears compressed and different in shape. Again the distance between the third ventricle and the mammillary recess is reduced in the Fkh5-/- mutant brain.

Medial mammillary body neurons project into the principal mammillary tract which divides and forms the mammillothalamic and mammillotegmental tracts (Guillery, 1955). Already at day 18.5 p.c., the efferent mammillothalamic shows disorganisation due to the absence of the medial mammillary nucleus (Fig. 7C,D). In the terminal differentiated mammillary body of 3-week old Fkh5-/- mice, both tracts are clearly affected. Whereas other tracts (e.g. fasciculus retroflexus) exhibit normal size, the mammillothalamic and mammillotegmental tracts are smaller than in the wild-type control (Fig. 7E,F).

\section{DISCUSSION}

We used targeted gene disruption to create a null-allele for the Fkh5 gene and to assess its in vivo function. The analysis reveals that this gene is essential for proper CNS development and function. Defects observed are consistent with its expression. In parallel, the targeted inactivation of $F k h 5$ was also performed by Labosky et al. (1997). We were able to confirm that the absence of $F k h 5$ is not lethal in utero and a general growth retardation of $F k h 5-/-$ mice. However, we did not observe an early developmental phenotype displaying abnormalities in the presomitic mesoderm or neural tube as described by Labosky et al. for a minority of Fkh5-Iembryos.

Additionally we also discovered striking differences in the anatomy of the hypothalamus, midbrain, and nurturing behaviour. Our $F k h 5-/-$ mice exhibit a clear morphological phenotype in the mammillary body region lacking the prominent medial mammillary nucleus and dysgenesis of the inferior colliculi in the caudal midbrain. Further, our behavioral analysis of homozygous-mutant mothers indicate that these mice display an abnormal nurturing response. Since both mutations are almost identical, it is likely that the observed differences are due to different genetic backgrounds of mice used for the analyses.

\section{Growth reduction and postnatal lethality of Fkh5-1- mice}

At birth, $F k h 5-/-$ mice are morphologically indistinguishable from their $F k h 5+/-$ and wild-type littermates. Genotypic analysis of neonatal offspring from heterozygous matings results
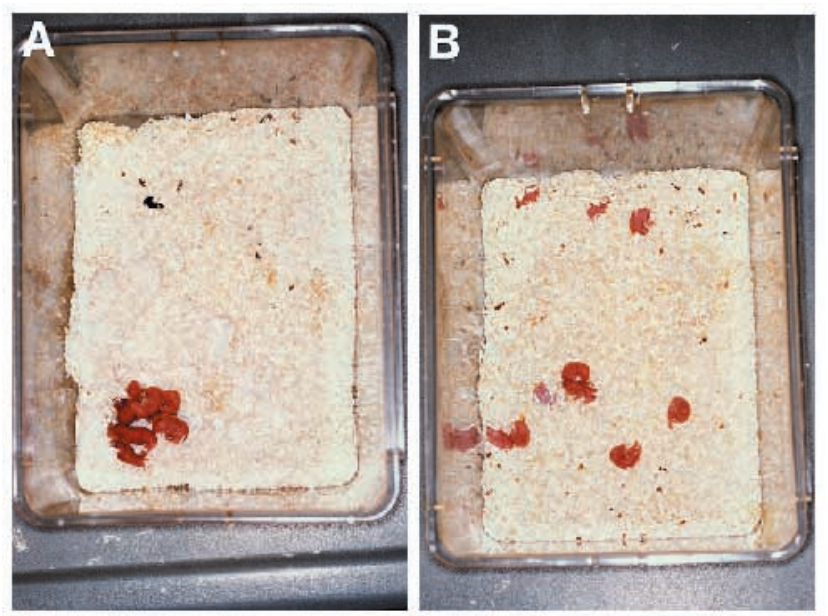

Fig. 3. Fkh5-/- mothers exhibit nurturing defects. View into cages of a (A) wild-type mother and (B) Fkh5-/- mother half a day after parturition. Whereas wild-type mothers build a nest and nurse their pups, Fkh5-/- mothers do not show any nest building activity and neglect and spread their pups. 
Fig. 4. Pax gene expression in the midbrain of day 10.5 p.c. embryos. $(\mathrm{A}, \mathrm{B})$ Whole-mount in situ hybridization with Pax 5 riboprobe performed on wild-type and $F k h 5-/-$ mice. (C,D) $\beta$ -

galactosidase staining indicating the presence of the $\operatorname{Pax} 7$ transgene in wild-type and Fkh5-/mice. The Pax gene expression pattern is not altered in the midbrain of Fkh5-I- mice. Scale bar indicates $500 \mu \mathrm{m}$.
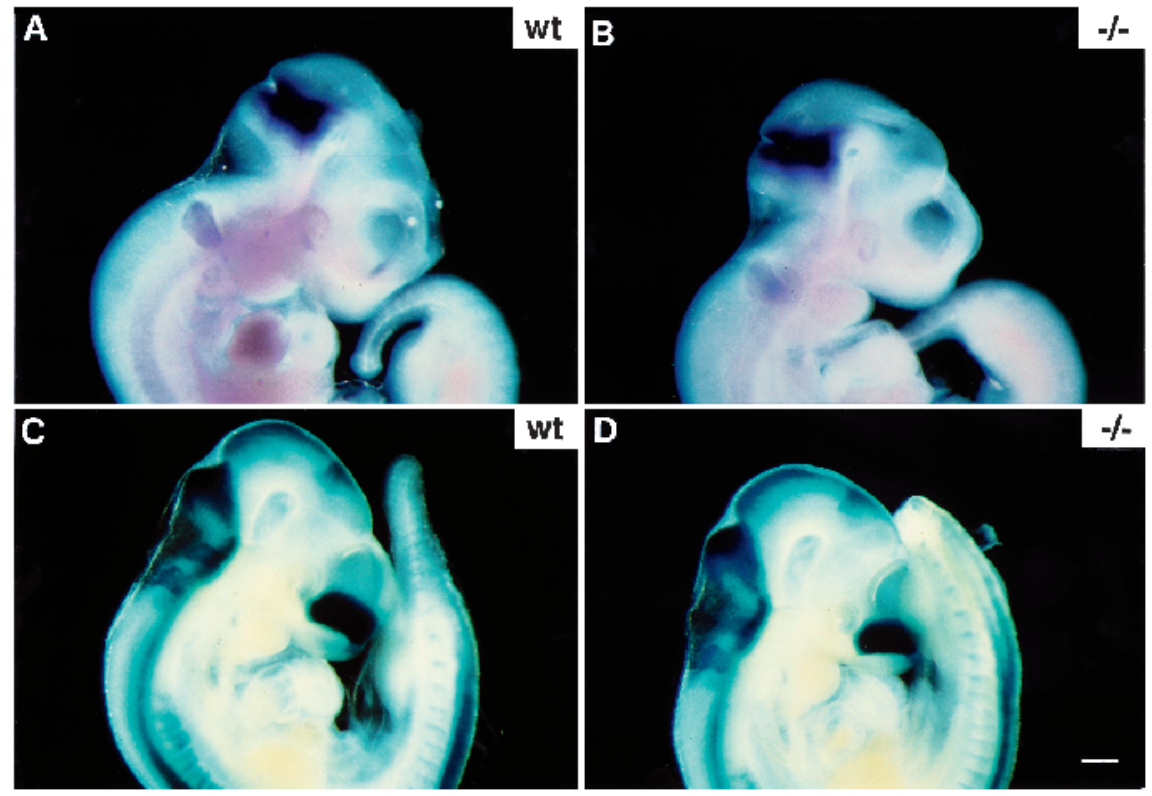

in the expected frequency, however the majority of mutant mice dies before weaning. Additionally, it becomes evident that the Fkh5-/- mice grow more slowly. The weight difference compared to wild-type and $F k h 5+/-$ mice is most pronounced within the first three weeks after birth. Growth retardation as a consequence of deregulation of growth hormone $(\mathrm{GH})$ production and secretion could be ruled out by Labosky et al. (1997) who demonstrated normal circulating GH levels in the blood and normal GH immunostaining in the pituitary of $F k h 5$ mutants. Thus, the $F k h 5$ growth retardation phenotype is different from other dwarf mutants which show defects in pituitary develop- ment (for review see Voss and Rosenfeld, 1992). Besides the neuroendocrine regulation, another major function of the hypothalamus is the control of feeding and drinking behavior (Mogenson, 1978). The observation that surviving Fkh5-/-mice never reach normal weight favours the idea that a behavioral feeding and drinking disorder contributes to the observed growth retardation and death. Since the mammillary body is connected to a variety of hypothalamic structures involved in feeding and drinking behavior, we suggest that the absence of mammillary body structures is responsable for the increased postnatal mortality and lower-than-average weight.
Fig. 5. Abnormal development of the inferior colliculi and the anterior cerebellum in Fkh5-/- mice. Dorsal view of whole brain preparations of 3-week old (A,D) wild-type, (B, E) $F k h 5+/-$ and (C,F) Fkh5-/- mice; (A-C) Bouins fixed or (D-F) glutaraldehyde fixed. (D-F) Brains are stained for $\operatorname{Pax} 7 \beta$-galactosidase activity. The black arrowheads denote the progressing overgrowth of the cerebellum (lobulus culmen) and the reduction of the inferior colliculi. (GI) Comparative histological analysis of parasagittal brain sections, stained with cresyl violet. The reduced inferior colliculus in the (I) Fkh5-/brain is denoted by a star. Note the partial $(\mathrm{H})$ or total $(\mathrm{I})$ overgrowth of the inferior colliculi by the lobulus culmen. SC, superior colliculus; IC, inferior colliculus; CU, culmen; wt, wild type; +/-, heterozygous mutant; $-/-$, homozygous mutant brain. Scale bar indicates $1.6 \mathrm{~mm}(\mathrm{~A}-\mathrm{F}) ; 400 \mu \mathrm{m}$ (G-I).
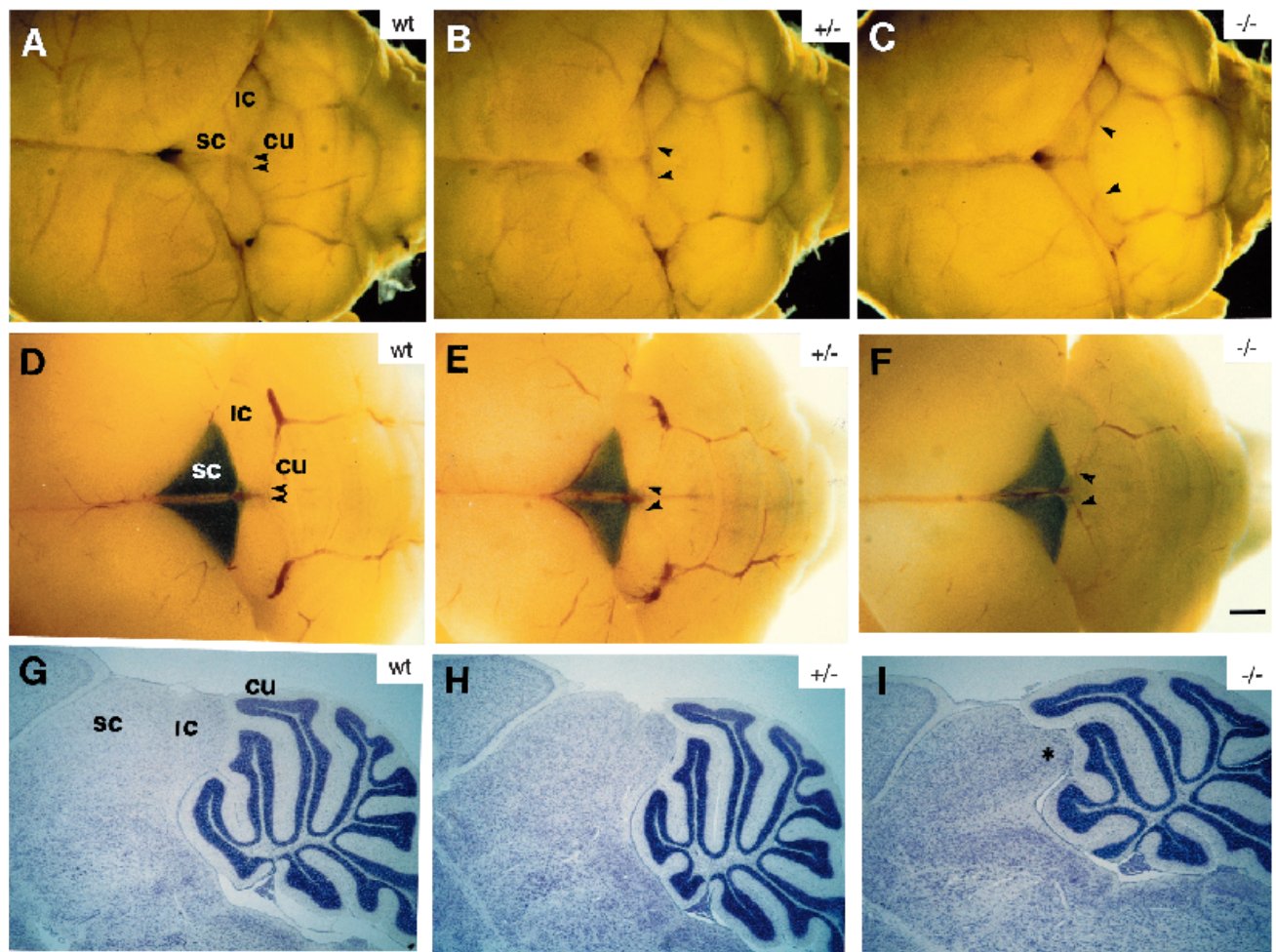

$+1-$
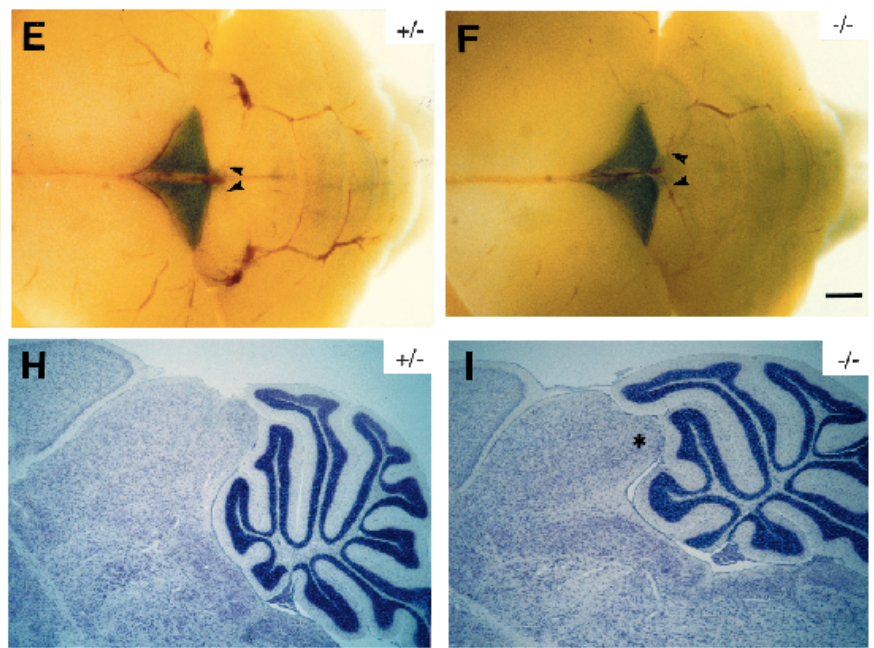

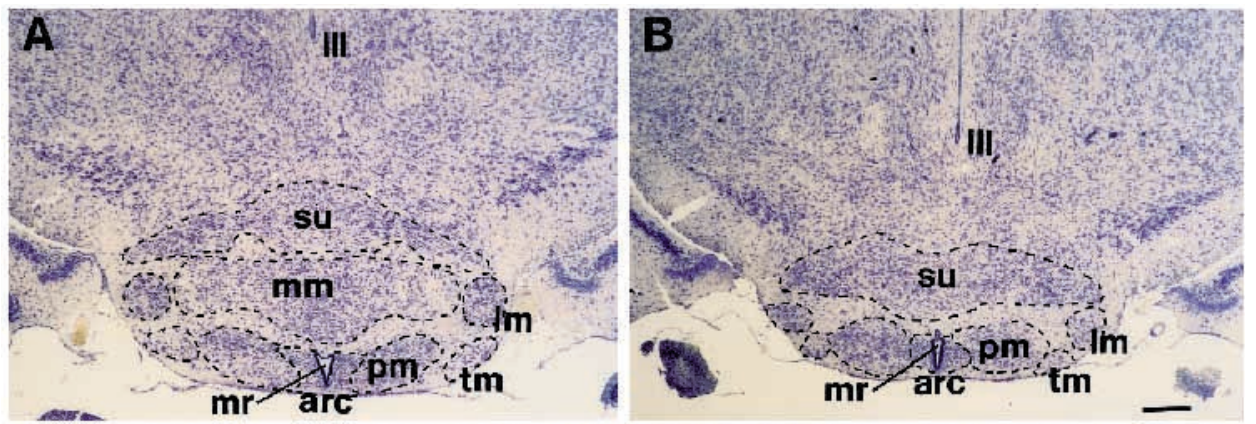

Fig. 6. The caudal hypothalamus is severely affected in Fkh5-/- mice. Histological analysis of the mammillary body region of 3-week old mice. Coronal $(\mathrm{A}, \mathrm{B})$ and parasagittal $(\mathrm{C}, \mathrm{D})$ sections of wild-type $(\mathrm{A}, \mathrm{C})$ and $F k h 5-/-(\mathrm{B}, \mathrm{D})$ brains stained with cresyl violet. The

mammillary body of $F k h 5-/-$ mice clearly lacks the prominent medial mammillary nucleus. Other mammillary nuclei are histologically normal. Note that the distance between the third ventricle and
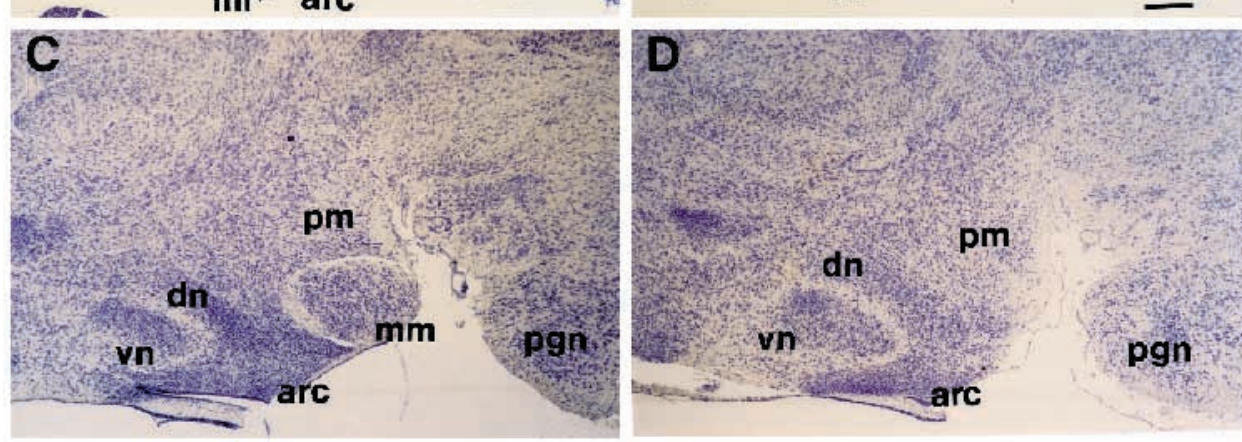
the mammillary recess in the mutant brain (B) is reduced due to the absence of the medial mammillary nucleus. arc, arcuate nucleus; dn, dorsomedial nucleus; lm, lateral mammillary nucleus; mm, medial mammillary nucleus; $\mathrm{mr}$, mammillary recess; pgn, pontine gray nucleus; pm, premammillary nuclei; su, supramammillary nucleus; tm, tuberomammillary nucleus; vn, ventromedial nucleus; III third ventricle. Scale bar indicates $200 \mu \mathrm{m}$.

\section{The role of $\boldsymbol{F k h 5}$ in midbrain development}

In headfold stage embryos $F k h 5$ is expressed in a defined region of the neuroectoderm fated to become diencephalon and mesencephalon (Tam, 1989). After neural tube closure, expression becomes restricted to the midbrain-hindbrain boundary and to the rostral tectum, forming gradients of expression in midgestation embryos. The expression gradient in the anterior tectum suggests an involvement in the estab-
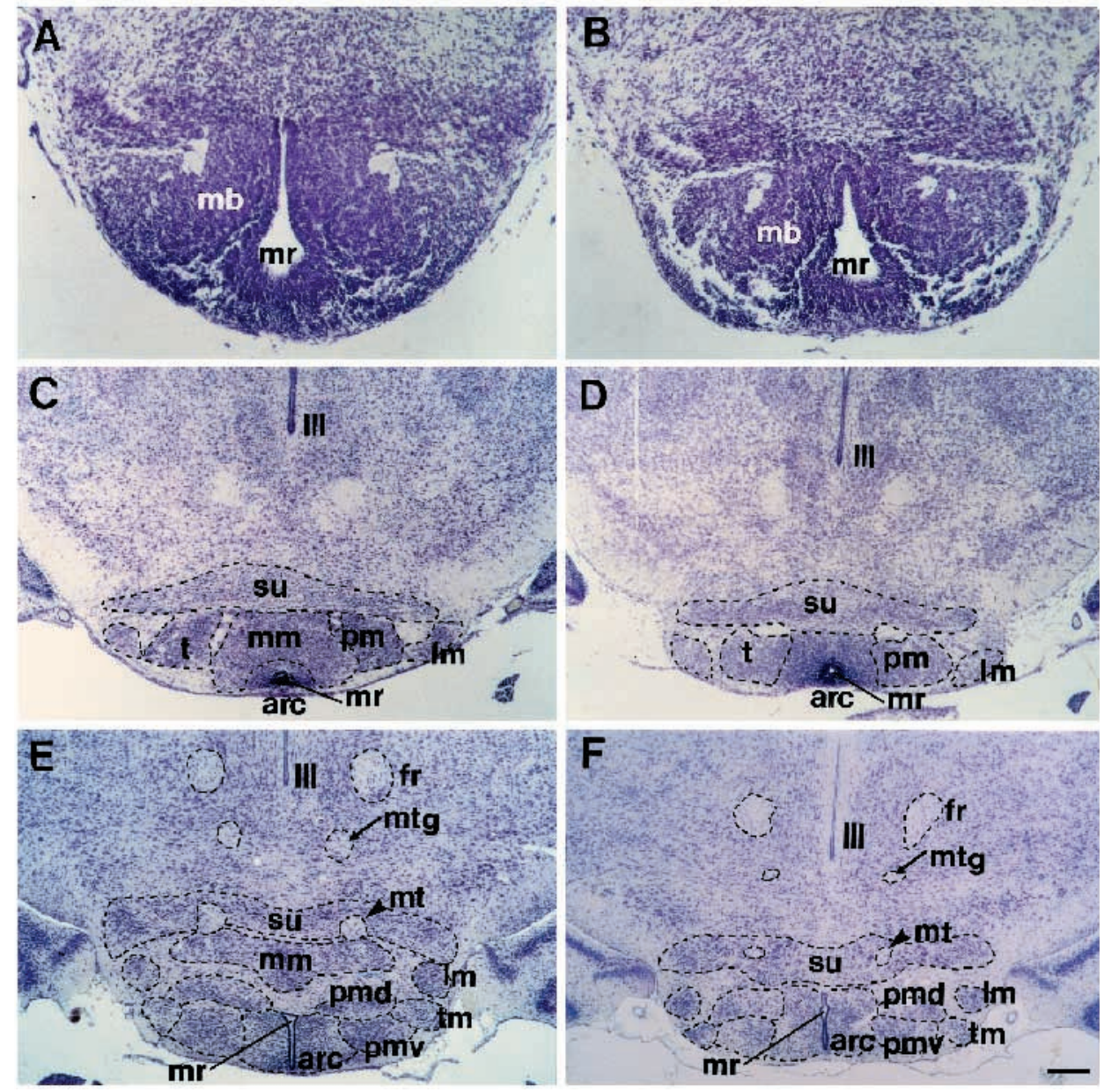

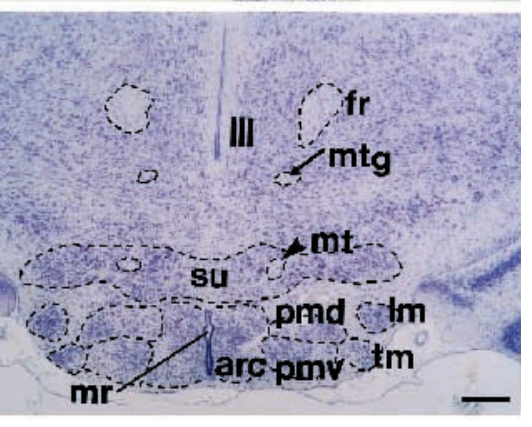

Fig. 7. Onset of the mammillary body phenotype and dygenesis of mammillary body projections. Coronal sections of the mammillary body region of (A,C,E) wildtype and (B,D,F) Fkh5-l- brains stained with cresyl violet. At day 16.5 p.c., the medial mammillary body of (B) Fkh5-/brains is smaller compared to (A) wild-type brains. (C,D) At day 18.5 p.c. it becomes evident that $F k h 5-/-$ mice fail to develop the medial mammillary nucleus and display dysgenesis of the mammillothalamic tract. A comparison of the mammillary body of 3-week (E) wild-type and (F) Fkh5-/brains reveals complete absence of the medial mammillary nucleus, which causes a reduction of the efferent mammillothalamic and the mammillotegmental tracts. arc, arcuate nucleus; fr, fasiculus retroflexus; $1 \mathrm{~m}$, lateral mammillary nucleus; $\mathrm{mb}$, mammillary body; mm, medial mammillary nucleus; $\mathrm{mr}$, mammillary recess; $\mathrm{mt}$, mammillothalamic tract; $\mathrm{mtg}$, mammillotegmental tract; pm, premammillary nuclei; pmd, dorsal premammillary nucleus; pmv, ventral premammillary nucleus; su, supramammillary nucleus; tm, tuberomammillary nucleus; III, third ventricle. Scale bar indicates $100 \mu \mathrm{m}$ (A, B); $200 \mu \mathrm{m}(\mathrm{C}-\mathrm{F})$. 
lishment of retinotectal projections. Other molecules showing a similar distribution in the tectum are RAGS, Enl and Elf-1, which have been shown to play a critical role in setting up a topographic map of projections (Itsaki et al., 1991; Cheng et al., 1995; Drescher et al., 1995; Logan et al., 1996). Supporting this hypothesis, the overexpression of the fork head genes, $B F 1$ and $B F 2$, in chick retina severely disturbs the growth of topographical projections from the retina to the anterior tectum, exhibiting distorted trajectories and aberrant projections (Yuasa et al., 1996). However, standard histological analysis of the pretectum and the superior colliculli in Fkh5-/- mice did not reveal any obvious alterations. Additionally, the superior colliculi are normal in size and lamination, from studies involving Pax7 expression analysis, arguing for its proper function (data not shown).

Expression in the caudal mesencephalon is detected during embryogenesis from day 9.5-14.5 p.c.. However, one aspect of the phenotype in Fkh5-I- mice is observed solely after birth. $F k h 5$ inactivation results in a size reduction of the medial inferior colliculi and an abnormal growth of the most anterior part of the cerebral vermis, the lobulus culmen. These data suggest Fkh5 to be a regulator of the midbrain-hindbrain region, a well analysed structure with organizing activity during embryogenesis. In this region genes like $W n t 1, E n 1, E n 2$ and Pax5 are described as important players (reviewed by Joyner, 1996). Mice lacking EnI or Wntl display substantial deletions in the posterior midbrain and in the cerebellum, resulting in neonatal lethality (McMahon and Bradley, 1990; Thomas and Capecchi, 1990; Wurst et al., 1994). Defects are already observed in these regions at day 9.5 p.c. in homozygous null-mice, just one day after initial expression. Although $F k h 5$ is expressed in early stages at the midbrain-hindbrain boundary, there is no evidence for differences in this region during embryogenesis. This may be due to redundancy with another fork head gene, Fkh2, expressed in the midbrain during development (Kaestner et al., 1995). Fkh2 shows $60 \%$ amino acid homology to the DNA-binding domain of $F k h 5$, suggesting that they may regulate common target genes. Functional redundancy has already been reported for the fork head genes sloppy paired 1 and 2 in Drosophila (Grossniklaus et al., 1992; Cadigan et al., 1994).

Similar to Fkh5, En2 and Pax5 are expressed early in midbrain development, and a phenotype in loss-of-function experiments is not apparent until after birth. En2 inactivation results in abnormal foliation of the cerebellum (Joyner et al., 1989). Pax5 null mutation causes defects in the posterior midbrain and the anterior cerebellum (Urbanek et al., 1994). Interestingly, Fkh5 and Pax 5 share not only a similar expression domain at the midbrain-hindbrain boundary during embryogenesis, but also show striking resemblances in phenotype upon gene inactivation. Both null mutations exhibit reduction of the central part of the inferior colliculi and abnormal cerebellar morphology. Pax5-/- mice display an altered foliation of the anterior cerebellum, whereas Fkh5-/- mice exhibit an elongation of the most anterior lobe of the cerebellar vermis. The cerebellar phenotype of both genes is surprising, since expression is never detected in the cerebellum. Transplantation experiments have demonstrated that cells of the dorsal midbrain and the midbrain-hindbrain boundary migrate into the cerebellum during development (Hallonet et al., 1990). The early expression of both genes in this region is possibly in cells that later migrate into the cerebellum. Similarities of expression and knock out data suggest that both genes interact during posterior midbrain development. However, analysis in Fkh5-/- mice did not reveal any alterations in Pax5 expression (Fig. 4A,B). Therefore, Pax 5 may be upstream of $F k h 5$ and will be examined in Pax 5 null-mice. Alternatively, both genes may act in independent genetic cascades in this brain region. Another similarity between $F k h 5$ and Pax5 is the intermediate phenotype observed in the posterior midbrain region. In $F k h 5+/-$ brains the medial portion of the inferior colliculi is intermediate in size between wild-type and $F k h 5-/-$ mice. This argues that the dose of the $F k h 5$ gene product is critical for the proper development of this brain structure. The size reduction of the inferior colliculi in Fkh5-/- and Fkh5+/- mice can possibly be explained by altered proliferation, apoptosis or migration.

Since the inferior colliculi are affected in Fkh5-/- and Fkh5 $+/-$ mutants, these mice may not capable of processing auditory information properly. Probable deficiencies in auditory function will be investigated in future experiments.

\section{Fkh5 is an essential regulator for mammillary body development}

High Fkh5 expression is observed in the mammillary body region from day 10.5 p.c. onwards. After birth, $F k h 5$ transcripts are localized in specific subnuclei of the mammillary body persisting into adulthood. Although Fkh5 is detected in the mammillary body region as early as day 10.5 p.c., there is no evidence from loss-of-function analysis that $F k h 5$ plays a role during early hypothalamus regionalization. One possible mechanism might be genetic redundancy. Recently, another related fork head gene, Fkh4 with a highly homologous winged helix domain (90\% amino acid homology) has been reported (Kaestner et al., 1996). Both genes are expressed in the early mammillary body region and make Fkh4 a good candidate to compensate for the absence of Fkh5. This may explain why defects in this region are only apparent after day 16.5 p.c. resulting in the lack of the prominent medial mammillary nucleus. Therefore, Fkh5 protein is indispensable for the development of the prominent medial mammillary nucleus.

There is evidence that the medial mammillary body plays a key role in spatial memory formation. Already a classic neuroanatomical circuit proposed by Papez (1937; 'Papez circuit') points to a function of the mammillary bodies in memory formation. Projections of this neuronal circuit interconnect the hippocampal formation, the anterior thalamic nuclei, the cingulate gyrus and the mammillary body (Swanson and Cowan, 1975; Swanson, 1987; Allen and Hopkins, 1989). Within this circuit the hippocampal-mammillary-anterior thalamic circuit is pivotal, since lesions, and in the case of the hippocampus also genetic studies, result in various forms of spatial learning and memory deficits (Weiskrantz, 1978; Tako et al., 1988; Aggleton et al., 1985, 1990, 1991; Hunt and Aggleton, 1991; Moser et al., 1993; Bach et al., 1995). In Fkh5-/- mice, the medial mammillary nucleus is absent, interrupting the Papez circuit and presumably leading to dysfunction in spatial memory consolidation.

Further evidence for a role in learning and memory arises from neuropathological studies of the amnesic Korsakoff syndrome. Patients displaying this syndrome are characterized by confusion and severe learning and memory deficits. In these patients thiamine deficiency results from continuos excessive alcohol consumption causing several neuropathological 
changes, most prominently in the mammillary bodies and the mammillothalamic tract (reviewed by Brierley, 1977; Kopelman, 1995). To establish animal models for functional studies of the mammillary body, neurosurgical lesions were performed in rodents and nonhuman primates using chemical or mechanical methods. These studies demonstrate the effect of mammillary body damage on different tasks analysing spatial memory. Alterations and impairments of spatial memory were discovered e.g. in T-maze, Morris water maze and eight-arm radial maze tasks (Rosenstock et al., 1977; Field et al., 1978; Tako et al., 1988; Saravis et al., 1990; Harper et al., 1994). From these data we anticipate that $F k h 5-/-$ mice also exhibit problems during spatial memory formation. Experiments to confirm this are currently in progress.

\section{Fkh5 plays a role for nurturing behavior}

Evidently, the $F k h 5$ mutation results in impaired nurturing behavior of $F k h 5-1-$ mothers. They neglect their pups which die shortly after birth. Nurturing of pups is an instinct-driven behavior that does not require experience related memory. Neuroanatomic lesions of the olfactory bulb (Gandelman 1971; Fleming, 1974, 1992), amygdala and preoptic area (Fleming 1980, 1983; Numan, 1988) produce deficient maternal reflexes, mainly caused by deficits in recognizing the pups or by an absent milk production secondary to neuroendocrine dysregulation. Since there is no implication for an anatomical defect in these brain regions and the mammary glands, we suggest that this abnormal behavior is due to the observed dysgenesis in the mammillary body. The impaired maternal behavior reported here is consistent with the view that limbic structures affected by the $F k h 5$ mutation are inbedded in neuronal circuits that mediate nurturing behavior. A similar behavioral phenotype was created by loss of function of the immediate early gene fos $B$ (Brown et al., 1996). These mice are unable to upregulate FosB synthesis in the preoptic area as it normally occurs in wild-type females exposed to new-born pups. Since the preoptic area is part of a neuronal pathway connecting the amygdala with the mammillary body, one can speculate that a functional neuronal circuit connecting these structures is important for a proper nurturing response. Therefore we propose that the mammillary body is another component of a neuronal network controlling nurturing behavior.

We thank Drs Gabriele Proetzel, Michael Wiles, Anastasia Stoykova, Luc St-Onge, Ken Ewan and Gonzalo Alvarez Bolado for critical reading, discussion and comments that helped to shape this manuscript. We also thank Dr Andràs Nagy for RI ES cells and Jens Krull for excellent technical assistance. We are also grateful to Dr Guillermo Oliver for the genomic $F k h 5$ clone, to Ralf Altschäffel for excellent photographic assistance and to the mouse house team. This work was supported by the Deutsche Forschungsgemeinschaft SFB 271.

\section{REFERENCES}

Acampora, D., Mazan, S., Lallemand, Y. Avantaggiato, V., Maury, M., Simeone, A. and Brulet, P. (1995). Forebrain and midbrain regions are deleted in Otx- $/-$ mutants due to a defective anterior neuroectoderm specification during gastrulation. Development 121, 3279-3290.

Aggleton, J. P. and Mischkin, M. (1985). Mammillary-body lesions and visual recognition in monkeys. Exp. Brain Res. 58, 190-197.

Aggleton, J. P., Hunt, P. R. and Shaw, C. (1990). The effects of mammillary body and combined amygdalar-fornix lesions on tests of delayed nonmatching-to-sample in the rat. Behav. Brain Res. 40, 145-157.
Aggleton, J. P., Keith, A. B. and Sahgal, A. (1991). Both fornix and anterior thalamic, but not mammillary, lesions disrupt delayed non-matching-toposition memory in rats. Behav. Brain Res. 44, 151-161.

Allen, G. V. and Hopkins, D. A. (1989). Mammillary body in the rat: topography and synaptology of projections from the subicular complex, prefrontal cortex, and midbrain tegmentum. J. Comp. Neurol. 286, 311-336.

Allen, N. D., Cran, D. G., Barton, S. C., Hettle, S., Reik, W. and Surani, M. A. (1988). Transgenes as probes for active chromosomal domains in mouse development. Nature 333, 852-855.

Altman, J. and Bayer, S. A. (1986). The development of the rat hypothalamus. Berlin: Springer.

Ang, S. and Rossant, J. (1994). HNF-3 $\beta$ is essential for node and notochord formation in mouse development. Cell 78, 561-574.

Ang, S. L., Wierda, A., Wong, D., Stevens, K., Cascio, S., Rossant, J. and Zaret, K. S. (1993). The formation and maintenance of the definitive endoderm lineage in the mouse: involvement of HNF3/forkhead proteins. Development 119, 1301-1315.

Asano, M. and Gruss, P. (1992). Pax-5 is expressed at the midbrain-hindbrain boundary during mouse development. Mech. Dev. 33, 27-38.

Bach, M. E., Hawkins, R. D., Osman, M., Kandel, E. R. and Mayford, M. (1995). Impairment of spatial but not contextual memory in CaMKII mutant mice with a selective loss of hippocampal LTP in the range of the theta frequency. Cell 81, 905-915.

Brierley, J. B. (1977). Neuropathology of amnesic states. In Amnesia, (ed. C.W.M. Whittey and O.L. Zangwill), pp. 199-223. London: Butterworths.

Brown, J.R., Ye, H., Bronson, R.T., Dikkes, P. and Greenberg, M.E. (1996). A defect in nurturing in mice lacking the immediate early gene fos B. Cell $\mathbf{8 6}$ 297-309.

Cadigan, K. M., Grossniklaus, U. and Gehring, W. J. (1994). Functional redundancy: the respective roles of the two sloppy paired genes in Drosophila segmentation. Proc. Natl. Acad. Sci. USA 91, 6324-6328.

Chalepakis, G., Stoykova, A., Wijnholds, J., Tremblay, P. and Gruss, P. (1993). Pax: Gene regulators in the developing nervous system. J. Neurobiol. 24, 1367-1384.

Cheng, H.-J., Nakamoto, M., Bergemann, A. D. and Flanagan, J. G. (1995). Complementary gradients in expression and binding of ELF-1 and Mek4 in development of the topographic retinotectal projection map. Cell 82, 371-381.

Clark, K., Halay, E., Lai, E. and Burley, S. (1993). Co-crystal structure of the HNF-3/fork head DNA-recognition motif resembles histone H5. Nature 364, 412-420.

Drescher, U., Kremoser, C., Handwerker, C., Loschinger, J., Noda, M. and Bonhoeffer, F. (1995). In vitro guidance of retinal ganglion cell axons by RAGS, a $25 \mathrm{kDa}$ tectal protein related to ligands for Eph receptor tyrosine kinases. Cell 82, 359-370.

Field, T. D., Rosenstock, J., King, E. C. and Greene, E. (1978). Behavioral role of the mammillary efferent system. Brain Res. Bull. 3, 451-456.

Fleming, A .S. and Rosenblatt, J. S. (1974). Olfactory regulation of maternal behavior in rats: I. Effects of olfactory bulb removal in experienced and inexperienced lactating and cycling females. J. Comp. Physiol. Psych. 86, 221-232.

Fleming, A. S., Vaccarino, F. and Luebke, C. (1980). Amygdaloid inhibition of maternal behavior in the nulliparous female rat. Physiol. Behav. 25, 731-743.

Fleming, A. S., Miceli, M. and Moretto, D. (1983). Lesions of the medial preoptic area prevent the facilitation of maternal behavior produced by amygdala deletions. Physiol. Behav. 31, 503-510.

Fleming, A. S., Gavarth, K. and Sarker, J. (1992). Effects of transections to the vomeronasal nerves or to the main olfactory bulbs on the initiation and long-term retention of maternal behavior in primiperous rats. Behav. Neur. Biol. 57, 177-188.

Gandelman, R., Zarrow, M. X., Denenberg, V. H. and Myers, M. (1971). Olfactory bulb removal eliminates maternal behavior in the mouse. Science 171, 210-211

Grossniklaus, U., Kurth Pearsen, R. and Gehring, W. J. (1992). The Drosophila sloppy paired locus encodes two proteins involved in segmentation that show homology to mammalian transcription factors. Genes Dev. 6, 1030-1051.

Guillery, R.W. (1955). A quantitative study of the mammillary bodies and their connexions. J. Anat. 89, 19-32.

Hallonet, M. E. R., Teillet, M.-A. and Le Douarin, N. M. (1990). A new approach to the development of the cerebellum provided by the quail-chick marker system. Development 108, 19-31.

Harper, D. N., Mc Lean, A. P. and Dalrymple-Alford, J. C. (1994). Forgetting in rats following medial septum or mammillary body damage Behav. Neurosci. 108, 691-702. 
Hunt, P. R. and Aggleton, J. P. (1991). Medial dorsal thalamic lesions and working memory in the rat. Behav. Neural Biol. 55, 227-246.

Itsaki, N., Ichijo, H., Hama, C., Matsuno, T. and Nakamura, H. (1991). Establishment of rostrocaudal polarity in tectal primordium : engrailed expression and subsequent tectal polarity. Development 113, 1133-1144.

Jostes, B., Walther, C. and Gruss, P. (1991). The murine paired box gene, $\operatorname{Pax} 7$, is expressed specifically during the development of the nervous and muscular system. Mech. Dev. 33, 27-38.

Joyner, A. L. (1996). Engrailed, Wnt and Pax genes regulate midbrainhindbrain development. Trends Genet. 12, 15-20.

Joyner, A. L., Kornberg, T., Coleman, K. G., Cox, D. R. and Martin, G. R. (1985). Expression during embryogenesis of a mouse gene with sequence homology to the Drosophila engrailed gene. Cell 43, 29-37.

Joyner, A. L., Skarnes, W. C. and Rossant, J. (1989). Production of a mutation in mouse $E n-2$ gene by homologous recombination in embryonic stem cells. Nature 338, 153-156.

Kaestner, K., Monaghan, A., Kern, H., Ang, S., Weitz, S., Lichter, P. and Schütz, G. (1995). The mouse $f k h-2$ gene. Implications for notochord, foregut, and midbrain regionalization. J. Biol. Chem. 270, 30029-30035.

Kaestner, K. H., Schütz, G. and Monaghan, A. P. (1996). Expression of the winged helix genes $f k h-4$ and $f k h-5$ defines domains in the central nervous system. Mech. Dev. 55, 221-230.

Kaufmann, E. and Knöchel, W. (1996). Five years on the wings of fork head. Mech. Dev. 57, 3-20.

Kopelman, M.D. (1995). The Korsakoff syndrome. Brit. J. Psychiatry 166, 154-173.

Labosky, P.A., Winnier, G.F., Sasaki, H., Blessing, M. and Hogan, B.L.M. (1996): The chromosomal mapping of four genes encoding winged helix proteins expressed early in mouse development. Genomics 34, 241-245.

Labosky, P.A., Winnier, G.E., Jetton, T. L., Hargett, L., Ryan, AimeeK. R., Rosenfeld, M.G., Parlow, A.F. and Hogan, B. L. (1997). The winged helix gene, $M f 3$, is required for normal development of the diencephalon and midbrain, postnatal growth and the milk-injection reflex. Development 124, 1263-1274.

Logan, C., Wizenmann, A., Drescher, U., Monschau, B., Bonhoeffer, F. and Lumbsden, A. (1996). Rostral optic tectum acquires caudal characteristics following ectopic Engrailed expression. Cur. Biol. 6, 1006-1014.

Mansour, S. L., Thomas, K. R. and Capecchi, M. R. (1988). Disruption of the prot-oncogene int-2 in mouse embryo-derived stem cells: a general strategy for targeting mutations to non-selectable genes. Nature 336, 348-352.

Mansouri, A., Stoykova, A., Torres, M. and Gruss, P. (1996). Dysgenesis of cephalic neural crest derivatives in Pax $7^{-1-}$ mutant mice. Development 122, 831-838.

Mogenson, G.J. (1978). Hypothalamic and other neural mechanisms for the control of food and water intakes. Current Studies of Hypothalamic Function 2, 93-106.

Moser, E., Moser, M.-B. and Andersen, P. (1993). Spatial learning impairments parallels the magnitude of dorsal hippocampal lesions, but is hardly present following ventral lesions. J. Neurosci. 13, 3916-3925.

Matsuo, I., Kuratani, S., Kimura, C., Takeda, N. and Aizawa, S. (1995). Mouse $O t \times 2$ functions in the formation and patterning of rostral head. Genes Dev. 9, 2646-2658.

McMahon, A. P. and Bradley, A. (1990). The Wnt-1 (int-1) proto-oncogene is required for development of a large region of the mouse brain. Cell 62, 10731085.

Monaghan, A. P., Kaestner, K. H., Grau, E. and Schütz, G. (1993). Postimplantation expression patterns indicate a role for the mouse forkhead/HNF-3 alpha, beta and gamma genes in determination of the definitive endoderm, chordamesoderm and neuroectoderm. Development 119, 567-578.

Nagy, A., Rossant, J., Nagy, R., Abramow-Newerly, W. and Roder, J. C. (1993). Derivation of completely cell culture-derived mice from early passage embryonic stem cells. Proc. Natl. Acad. Sci. USA 90, 8424-8428.

Numan, M., Coromas, K.P., Numan, M.J., Factor, E.M., Piers, W.D. (1988). Axon sparing lesions in the preoptic area and substantia innominata disrupt maternal behavior in rats. Behav. Neurosci. 102, 381-396.

Papez, J. W. (1937). A proposed mechanism of emotion. Arch. Neurol. Psychiatry 38, 725-743.

Pellegrini, M., Mansouri, A., Simeone, A., Boncinelli, E. and Gruss, P. (1996). Dentate gyrus formation requires Emx2. Development 122, 39933898.

Price, M., Lemaistre, M., Pischetola, M., Di Lauro, R. and Duboule, D. (1991). A mouse gene related to Distal-less shows a restricted expression in the developing forebrain. Nature 351, 748-751.
Qiu, M., Bulfone, A., Martinez, S., Meneses, J., Shimamura, K., Pedersen, R. and Rubenstein, J. (1995). Null mutation of $D l x$-2 results in abnormal morphogenesis of proximal first and second branchial arch derivatives and abnormal differentiation in the forebrain. Genes Dev. 9, 2523-2538.

Robertson, E. J. (1987). Embryo-derived stem cell lines. In Teratocarcinomas and Embryonic Stem Cells. A Practical Approach (ed. E. J. Robertson), pp. 71-112. Oxford: IRL Press.

Rosenstock, J., Field, T. D. and Greene, E. (1977). The role of mammillary bodies in spatial memory. Exp. Neurol. 55, 340-352.

Saravis, S., Sziklas, V. and Petrides, M. (1990). Memory for places and the region of the mammillary bodies in rats. Eur. J. Neurosci. 2, 556-564.

Sasaki, H. and Hogan, B. L. (1994). $H N F-3 \beta$ as a regulator of floor plate development. Cell 76, 103-115.

Sasaki, H. and Hogan, B. L. M. (1993). Differential expression of multiple fork head related genes during gastrulation and axial pattern formation in the mouse embryo. Development 118, 47-59.

Simeone, A., Acampora, D., Gulisano, M., Stornaiuolo, A. and Boncinelli, E. (1992a). Nested expression domains of four homeobox genes in developing rostral brain. Nature 358, 687-690.

Simeone, A., Gulisano, M., Acampora, D., Stornaiuolo, A., Rambaldi, M. and Boncinelli, E. (1992b). Two vertebrate homeobox genes related to the Drosophila empty spiracles gene are expressed in the embryonic cerebral cortex. EMBO J. 11, 2541-2550.

Soriano, P., Montgomery, C., Geske, R. and Bradley, A. (1991). Targeted disruption of the $c$-src proto-oncogene leads to osteopetrosis in mice. Cell $\mathbf{6 4}$ 693-702.

Stoykova, A. and Gruss, P. (1994). Roles of Pax-genes in developing and adult brain as suggested by expression patterns. J. Neurosci. 14, 1395-1412.

Swanson, L. W. (1987). Integrated systems of the CNS. In Handbook of Chemical Neuroanatomy, (ed. Björklund, A., Hökfelt, T. and Swanson, L.W.), pp. 1-124. Amsterdam: Elsevier.

Swanson, L. W. and Cowan, W. M. (1975). Hippocampo-hypothalamic connections: origin in subicular cortex, not ammon's horn. Science 189, 303304.

Tako, A. N., Berachochea, D. J. and Jaffard, R. (1988). Accelerated forgetting of spatial information following mammillary-body lesions in mice: Effects of context change on retention-test performance. Psychobiol. 16, 45-53.

Tam, P. P. L. (1989). Regionalisation of the mouse embryonic ectoderm: allocation of prospective ectodermal tissues during gastrulation. Development 107, 55-67.

Tao, W. and Lai, E. (1992). Telencephalon-restricted expression of $B F-1$, a new member of the $H N F-3 /$ fork head gene family in the developing rat brain. Neuron 8, 957-966.

Thomas, K. R. and Capecchi, M. R. (1990). Targeted disruption of the murine int-1 proto-oncogene resulting in severe abnormalities in midbrain and cerebellar development. Nature 346, 847-850.

Urbanek, P., Wang, Z. Q., Fetka, I., Wagner, E. F. and Busslinger, M. (1994). Complete block of early B cell differentiation and altered patterning of the posterior midbrain in mice lacking Pax5/BSAP. Cell 79, 901-912.

Voss, J. W. and Rosenfeld, M. G. (1992). Anterior pituitary development: short tales from dwarf mice. Cell 70, 527-530.

Weigel, D., Jürgens, G., Küttner, F., Seifert, E. and Jäckle, H. (1989). The homeotic gene fork head encodes a nuclear protein and is expressed in the terminal regions of the Drosophila embryo. Cell 57, 645-658.

Weinstein, D. C., Ruiz i Altaba, A., Chen, W. S., Hoodless, P., Prezioso, V. R., Jessell, T. M. and Darnell, J. E. (1994). The winged-helix transcription factor $H N F-3 \beta$ is required for notochord development in the mouse embryo. Cell 78, 575-588.

Weiskrantz, L. (1978). A comparison of hippocampal pathology in man and other animals. In Functions of the Septo-Hippocampal System (ed. Elliot, K., and Whelan, J.) Amsterdam: Elsevier.

Wilkinson, D. G. (1992). In Situ Hybridisation; A Practical Approach. London: Oxford University Press.

Wurst, W., Auerbach, A. B. and Joyner, A. L. (1994). Multiple developmental defects in Engrailed-1 mutant mice: and early mid-hindbrain deletion and patterning defects in forelimbs and sternum. Development 120, 2065-2075.

Xuan, S., Baptista, C. A., Balas, G., Tao, W., Soares, V. C. and Lai, E. (1995). Winged helix transcription factor $B F-1$ is essential for the development of the cerebral hemispheres. Neuron 14, 1141-1152.

Yuasa, J., Hirano, S., Yamagata, M. and Noda, M. (1996). Visual projection map specified by topographic expression of transcription factors in the retina. Nature 382, 632-635.

(Accepted 6 September 1997) 